\title{
MEDIA BONEKA TANGAN DALAM METODE BERCERITERA UNTUK MENANAMKAN KARAKTER POSITIF KEPADA SISWA SEKOLAH DASAR
}

\author{
Joko Sulianto, Mei Fita Asri Untari, Fitri Yulianti \\ Pendidikan Guru Sekolah Dasar Universitas PGRI Semarang \\ sulianto.jo@gmail.com
}

\begin{abstract}
The purpose of teaching process is on the way of developing students' positive characters. The students need something they like to learn, understand, and apply those characters. Hand-puppets can be chosen as the media. The puppets' characters (or the actors) are created based on the selected story which can gain students' positive characters. It is an $R$ and $D$ research. It was conducted on 6 steps of research activities: collecting data, planning, developing draft of product, testing, revising the result, and developing final product. This research will be finished in 2 years. The results of the first year research were: hand-puppets' profiles, hand-puppets actors, and experts' judgments. The students and the teachers explained that they needed story books and hand-puppets as their teaching supporting media using story-telling method. Hand-puppets which were made of colorful flannel and cotton fabric should be presented in colorful, eye-catching figures to attract the students' attention.
\end{abstract}

Keywords: Character building, hand-puppets, story-telling method

\begin{abstract}
ABSTRAK
Pembelajaran harus mengutamakan pengembangan kemampuan dan pembentukan karakter (character building) serta akhlak mulia (akhlaqul karimah) siswa. Siswa akan lebih tertarik dan mudah dalam belajar jika penanaman akhlak mulia disampaikan melalui hathal yang mereka sukai, contohnya dengan boneka tangan. Media ini disesuaikan bentuk dan karakter tokoh-tokohnya dengan isi cerita yang digunakan. Penelitian ini menggunakan metode penelitian pengembangan ( $R$ and $D$ ) yang dilaksanakan dalam 6 (enam) langkah penelitian, yaitu: pengumpulan data, perencanaan, pengembangan draf, pengujicobaan awal, perevisian hasil uji coba, dan penyempurnaan produk. Penelitian ini direncanakan akan dilaksanakan selama 2 tahun. Hasil yang diperoleh di tahun pertama berupa profil media boneka tangan yang cocok dalam kegiatan berceritera, tokoh-tokoh boneka tangan, dan penilaian dari ahli (experts' judgments). Siswa dan guru menginginkan media pendukung dalam kegiatan bercerita berupa buku cerita beserta tokohtokohnya dalam bentuk boneka tangan. Media boneka ini dibuat dari kain katun dan atau flannel berwarna cerah untuk menarik perhatian dan minat siswa.
\end{abstract}

Kata Kunci: Berceritera, budi pekerti, pengembangan media boneka tangan

Penanaman karakter akhlak mulia sejak usia dini sangatlah penting. Banyak sekali generasi muda yang telah melupakan budi pekerti, terutama budaya timur karena mereka telah dikuasai oleh budaya barat. Namun pendidikan budi pekerti dirasa sangat menyulitkan dan membosankan bagi siswa dan guru karena pendidikan budi pekerti hanya disampaikan melalui hafalan-hafalan akan sikap-sikap baik dan buruk dalam nilai-nilai budi pekerti tanpa diadakan pembiasaan tingkah laku, dan lain lain. 
Dalam sebuah pernyataan, Zuriah (2007) menjelaskan bahwa pendidikan budi pekerti bertujuan untuk mengembangkan watak atau tabiat siswa dengan cara menghayati nilai-nilai keyakinan masyarakat sebagai kekuatan moral dalam kehidupan melalui kejujuran, dapat dipercaya, disiplin, dan kerja sama yang menekankan ranah afektif tanpa meninggalkan ranah kognitif dan psikomotorik. Dengan kondisi tersebut, guru dan orang tua dapat memberikan alternatif kegiatan penanaman budi pekerti melalui kegiatan bercerita. Anak pun akan memiliki pengalaman melalui cerita yang diperankan oleh tokoh-tokohnya. Guru dan orang tua pun dapat menggiring anak dalam menyimpulkan nilai-nilai budi pekerti yang ada dalam cerita atau wacana. Pembelajaran budi pekerti melalui kegiatan bercerita melalui media boneka tangan dapa memaksimalkan kompetensi budi pekerti serta memaksimalkan kemampuan berbahasa siswa.

Kegiatan bercerita dengan boneka tangan ini selaras dengan pendapat dari Suparno (2002: 42) yang menawarkan empat model penyampaian pembelajaran moral dan budi pekerti, yaitu: model sebagai mata pelajaran tersendiri, model terintegrasi dalam semua mata pelajaran, model di luar pengajaran, dan model gabungan. Dari keempat model penyampaian pembelajaran moral dan budi pekerti, model pembelajaran ketiga — pembelajaran terintegrasi_akan lebih memudahkan penanaman budi pekerti dan lebih efektif, karena semua guru terlibat di dalam proses penanaman moral dan budi pekerti melalui mata pelajaran yang diampu oleh masing-masing guru. Manfaat dari kegiatan bercerita menurut tulisan dalam sebuah situs (Administrator, -) adalah: mengembangkan daya imajinasi anak, meningkatkan keterampilan dalam berbahasa, mengembangkan minat baca anak, membangun kecerdasan emosional anak, dan membentuk rasa empati anak.

Siswa SD mempunyai daya konsentrasi rata-rata dalam 5-8 menit untuk menyimak cerita. Oleh karena itu, dalam bercerita sebaiknya menggunakan media bercerita diselingi dengan nyanyian, tepukan, dan ingteraksi siswa dan guru. Untuk membuat keingintahuan dan konsentrasi siswa meningkat, dipilihlah media belajar yang dekat dengan dunia anak namun tetap mampu menawarkan pola keteladanan bagi para siswa. Media belajar sendiri merupakan alat yang secara fisik digunakan untuk menyampaikan isi materi pengajaran yang antara lain terdiri atas: buku, tape recorder, film, foto, grafik, kaset video kamera, televisi, komputer, dan lain-lain. Jadi, media adalah komponen sumber belajar atau peralatan fisik yang mengandung materi pembelajaran di lingkungan yang dapat merangsang siswa untuk belajar. (Gagne dan Briggs, dalam Arsyad, 2000).

Media boneka tangan yang akhirnya dipilih dan dibahas dalam makalah ini adalah boneka dijadikan sebagai media atau alat bantu yang digunakan guru dalam kegiatan pembelajaran yang terbuat dari potongan kain flanel, katun, kaos tangan, kaos kaki, dan sebagainya. Kemudian dibentuk dan dihias sedemikian rupa sehingga dapat ditampilkan menjadi beragam tokoh dengan karakter masing-masing yang disuguhkan dalam penampilan setiap karakter boneka. Dinamakan boneka tangan karena para pemain (guru, siswa, atau orang tua) memainkannya dengan cara memasukkan telapak tangan mereka ke dalam boneka.

Hal ini selaras dengan pendapat Gunarti (2010: 5-20) tentang definisi dan gambaran boneka tangan. Menurut pendapatnya, boneka tangan adalah boneka yang ukurannya lebih besar dari boneka jari dan bisa dimasukkan ke tangan. Jari tangan bisa dijadikan pendukung gerakan tangan dan kepala boneka. Jadi pengertian media boneka tangan adalah boneka dijadikan sebagai media atau alat bantu yang digunakan guru dalam kegiatan pembelajaran, yang ukurannya lebih besar dari boneka jari dan bisa dimasukkan ke tangan. (Sulianto, et al, 2014: 8)

Masih menurut Gunarti (2010: 5-20), di dalam kegiatan bercerita dengan menggunakan boneka tangan, sebaiknya diperhatikan hal-hal sederhana tetapi penting sebagai berikut. 
a. Hendaknya guru/pencerita hafal isi cerita.

b. Ada baiknya menggunakan skenario cerita.

c. Latihlah suara agar dapat memiliki beragam karakter suara yang dibutuhkan dalam bercerita. Misal suara anak-anak, suara nenek-nenek, suara ibu-ibu, suara binatang dan lain-lain.

d. Gunakan boneka yang menarik dan sesuai dengan dunia anak serta mudah dimainkan oleh guru atau orang tua maupun anak-anak.

e. Boneka yang digunakan bisa lebih dari satu, dengan jumlah maksimal 8 buah dengan bentuk yang berlainan agar siswa tidak kesulitan menghafal tokoh cerita.

f. Apabila menggunakan satu boneka, maka percakapan atau cerita dilakukan antara anak dengan boneka yang disuarakan oleh guru.

g. Apabila menggunakan dua boneka maka percakapan atau alur cerita dilakukan oleh kedua boneka tersebut yang disuarakan oleh guru atau orang tua dengan karakter suara yang berbeda. Anak menyimak percakapan dan jalan cerita yang disajikan.

h. Penggunaan lebih dari dua boneka maka percakapan atau alur cerita dilakukan oleh kedua boneka tersebut yang disuarakan oleh guru atau orang tua dengan karakter suara yang berbeda. Agar jalan cerita terdengar indah, dipermanis dengan alunan musik.

Boneka sebagai media cerita memiliki banyak kelebihan dan keuntungan. Anak-anak pada umumnya menyukai boneka, sehingga cerita yang dituturkan lewat karakter boneka jelas akan mengundang minat dan perhatiannya. Anak-anak juga bisa terlibat dalam permainan boneka dengan ikut memainkan boneka. Hal ini berarti, boneka bisa menjadi pengalih perhatian anak sekaligus media untuk berekspresi atau menyatakan perasaannya. Bahkan boneka bisa mendorong tumbuhnya fantasi atau imajinasi anak (Gunarti, 2010).

Dari teori tersebut dapat ditarik sebuah kesimpulan bahwa boneka tangan berfungsi sebagai media perantara yang digunakan untuk melibatkan anak ke dalam cerita yang sedang disampaikan agar anak mampu menangkap isi pembelajaran yang disampaikan oleh guru. Dengan media boneka tangan anak tertarik untuk berimajinasi, kemudian berusaha mencari kosa kata yang tepat untuk mengungkapkan ide yang ada pada diri mereka. (Sulianto, et al, 2014: 10)

Penelitian tentang penggunaan media boneka tangan dalam kegiatan bercerita untuk menanamkan budi pekerti dilaksanakan dalam 2 (dua) tahun. Tujuan dari penelitian di tahun pertama ini adalah: (1) menganalisis kebutuhan guru dan siswa dalam proses pembelajaran bercerita, (2) mengetahui profil cerita anak yang sesuai dengan kondisi siswa SD, (3) mengetahui profil media boneka tangan sesuai dengan analisis kebutuhan, dan (4) membuat prototype media boneka tangan yang telah divalidasi oleh ahli.

Urgensi dari penelitian ini adalah: (1) pengembangan media boneka tangan dalam kegiatan bercerita dapat dijadikan alternatif untuk mengatasi masalah dalam masyarakat yang sangat kompleks terkait dengan pendidikan karakter, (2) media boneka tangan dapat menjadi media belajar bahasa yang sekaligus juga dapat mengajarkan budi pekerti melalui kegiatan bercerita kepada siswa, (3) media belajar boneka tangan dapat kembali menempatkan posisi anak sebagai warga dari masyarakat yang membutuhkan orang lain dalam kehidupannya, yang tetap butuh berinteraksi dengan orang lain, dan butuh bekerja dalam kelompok bersama dengan teman-teman sebayanya, dan (4) media boneka tangan ini mampu mengoptimalkan potensi guru dalam menyusun cerita, menyusun skenario pertunjukkan boneka tangan, dan membuat tokoh-tokoh boneka tangan yang sesuai dengan cerita. 


\section{METODE}

Penelitian ini menggunakan pendekatan penelitian dan pengembangan ( $R$ and $D)$ yang memuat 10 (sepuluh) langkah penelitian yang selanjutnya diringkas menjadi 6 (enam) langkah penelitian, yaitu: (1) penelitian dan pengumpulan data/research and collecting information, (2) perencanaan/planning, (3) pengembangan draf produk/develop preliminary form of product, (4) uji coba lapangan tahap awal/preliminary field testing, (5) merevisi hasil uji coba/main product revision, dan (6) penyempurnaan product akhir/final product revision.

Keenam langkah tersebut akan dilaksanakan dalam 2 (tahap) selama 2 tahun. Pada tahun pertama ini, peneliti memfokuskan kegiatan penelitian pada 3 tahapan pertama dari keenam langkah di atas, yaitu dari langkah 1 sampai dengan 3.

Subyek penelitian ini adalah guru SD kelas V dan siswa kelas V SD yang berdomisili di Kota Semarang dan dosen ahli yang berprofesi sebagai dosen (dari bidang ilmu kebahasaan, sastra, dan media) atau sastrawan yang bertindak sebagai ahli pemberi nilai terhadap pengambangan boneka tangan. Dengan menggunakan teknik pengambilan sampel bertujuan (purposive sampling), diperoleh sampel penelitian dari SD negeri, SD swasta umum, dan SD Islam.

Instrumen yang digunakan dalam penelitian ini adalah angket kebutuhan terhadap guru, siswa, dan orang tua tentang budi pekerti dan kegiatan bercerita, dan instrumen tentang penilaian media boneka tangan oleh ahli pendidikan dan media boneka tangan. Desain penelitian yang telah dilakukan pada tahun pertama dapat dilihat pada bagan di bawah ini:

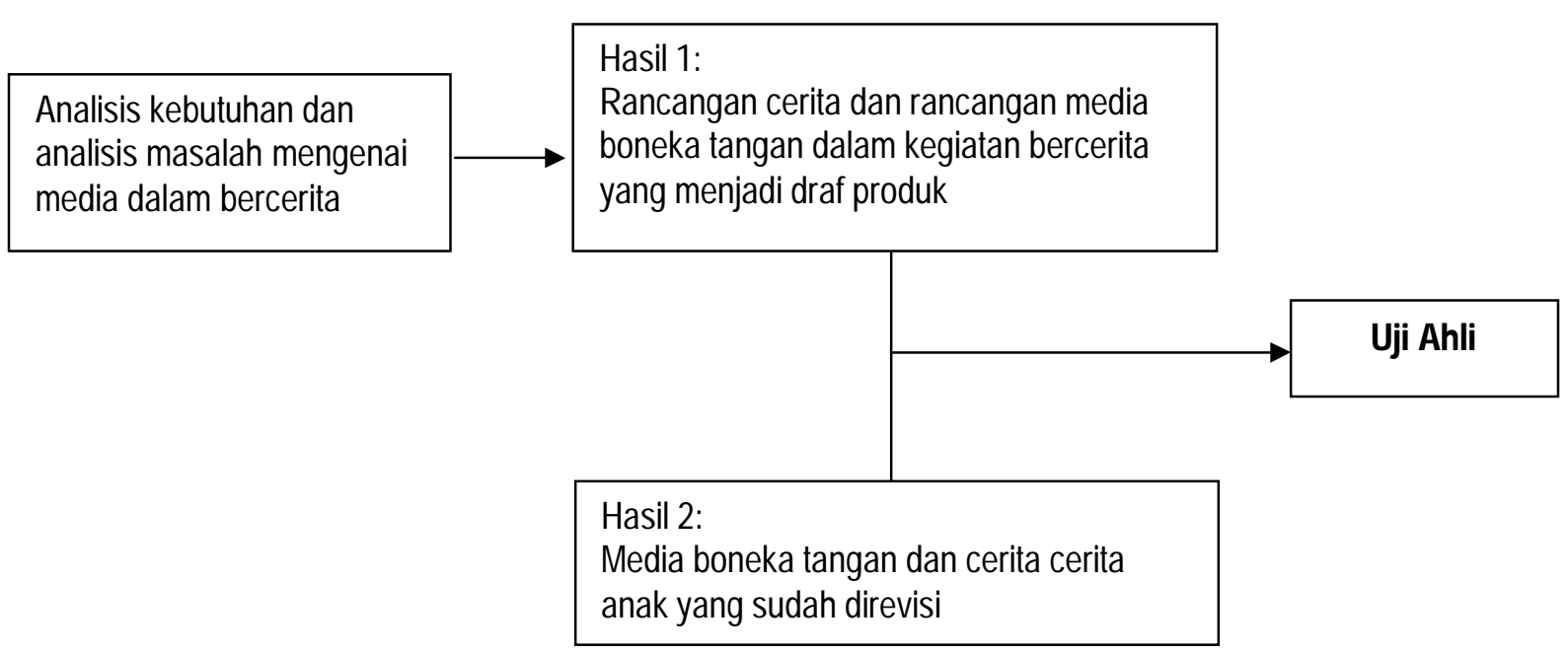

\section{HASIL DAN PEMBAHASAN}

Hasil penelitian tahun pertama yang kami paparkan ini berisi hasil analisis kebutuhan (kebutuhan terhadap cerita bagi anak menurut anak dan orang tua, pembelajaran bercerita dalam proses pembelajaran, kriteria cerita anak pada aspek tokoh cerita, kriteria cerita anak, profil media boneka tangan, profil kegiatan bercerita), dan pengembangan media boneka tangan dalam kegiatan bercerita yang masih bersifat awal. Hasil analisis kebutuhan cerita bagi anak dijabarkan dalam bagan di Tabel 1 berikut. 
Tabel 1. Analisis Kebutuhan Cerita Bagi Anak

\begin{tabular}{|c|c|c|c|c|c|c|c|}
\hline \multirow{3}{*}{ Indikator } & \multirow{3}{*}{ Jawaban } & \multicolumn{6}{|c|}{ Sekolah } \\
\hline & & \multicolumn{2}{|c|}{ SD N Pendrikan Lor 02} & \multicolumn{2}{|c|}{ SD Bungangan 03} & \multicolumn{2}{|c|}{ MI Nasharul Fajar } \\
\hline & & Jml & Ket & Jml & Ket & Jml & Ket \\
\hline \multirow[t]{2}{*}{ Suka membaca cerita } & $\mathrm{Ya}$ & 62 & Pilihan & 53 & Pilihan & 69 & Pilihan \\
\hline & Tidak & 6 & & 3 & & 1 & . \\
\hline \multirow{5}{*}{$\begin{array}{l}\text { Suka mendengarkan atau } \\
\text { menonton cerita } \\
\text { Jumlah membaca cerita dalam } \\
\text { sebulan }\end{array}$} & $\mathrm{Ya}$ & 57 & Pilihan & 50 & Pilihan & 67 & Pilihan \\
\hline & Tidak & 11 & - & 6 & - & 3 & - \\
\hline & $<5$ cerita & 40 & Pilihan & 42 & Pilihan & 42 & Pilihan \\
\hline & $5-10$ cerita & 24 & - & 6 & - & 21 & - \\
\hline & $>10$ cerita & 4 & - & 8 & - & 7 & - \\
\hline \multirow{3}{*}{$\begin{array}{l}\text { Jumlah mendengarkan cerita } \\
\text { dalam sebulan }\end{array}$} & $<5$ cerita & 36 & Pilihan & 39 & Pilihan & 43 & Pilihan \\
\hline & $5-10$ cerita & 19 & - & 10 & - & 17 & - \\
\hline & $>10$ cerita & 13 & - & 7 & & 10 & - \\
\hline \multirow{3}{*}{$\begin{array}{l}\text { Jumlah cerita anak yang } \\
\text { diketahui }\end{array}$} & $<10$ cerita & 45 & Pilihan & 41 & Pilihan & 40 & Pilihan \\
\hline & $10-20$ cerita & 15 & - & 12 & - & 20 & - \\
\hline & $>20$ cerita & 8 & . & 3 & . & 10 & - \\
\hline
\end{tabular}

Dari data Tabel 1, dapat disimpulkan kalau kebutuhan cerita bagi anak sangatlah penting. Sebagian besar siswa pun menyukai kegiatan membaca, mendengarkan, dan menonton cerita.

Kebutuhan cerita anak bagi siswa menurut orang tua tampak pada Tabel 2.

Tabel 2. Analisis Kebutuhan Cerita Anak Bagi Aiswa Menurut Orang Tua

\begin{tabular}{lccc}
\hline Indikator & Jawaban & Jumlah & Keterangan \\
\hline Anak suka membaca cerita & Ya & 10 & Pilihan \\
& Tidak & 0 & - \\
Anak senang mendengarkan atau menonton cerita & Tidak Tahu & 0 & - \\
& Ya & 10 & Pilihan \\
Sumber cerita anak & Tidak & 0 & - \\
& Tidak tahu & 0 & - \\
& Buku pelajaran & 10 & Pilihan \\
Frekuensi orang tua bercerita dalam sebulan & Buku cerita & 5 & - \\
& Majalah & 5 & - \\
& Orang tua & 3 & - \\
& $<5$ cerita & 10 & Pilihan \\
& $5-10$ cerita & 0 & - \\
\hline
\end{tabular}

Dari Tabel 2 diketahui bahwa orang tua mengetahui bahwa anak-anak mereka suka membaca, mendengarkan atau menonton buku cerita. Para orang tua pun mengakui bahwa buku yang paling banyak dimiliki oleh anak-anak mereka adalah buku pelajaran. Hanya sebagian kecil yang memiliki koleksi buku cerita anak-anak. Selain itu, para orang tua pun mengakui kalau mereka meluangkan hanya sedikit waktu untuk bercerita kepada anak, yaitu kurang dari lima kali dalam satu bulan. 
Tabel 3. Gambaran Tentang Pembelajaran Membaca

\begin{tabular}{|c|c|c|c|c|c|c|c|}
\hline \multirow{3}{*}{ Indikator } & \multirow{3}{*}{ Jawaban } & \multicolumn{6}{|c|}{ Sekolah } \\
\hline & & \multicolumn{2}{|c|}{$\begin{array}{l}\text { SDN Pendrikan Lor } \\
02 \\
\end{array}$} & \multicolumn{2}{|c|}{ SD Bungangan 03} & \multicolumn{2}{|c|}{ MI Nasharul Fajar } \\
\hline & & $\mathrm{Jml}$ & Ket & $\mathrm{Jml}$ & Ket & $\mathrm{Jml}$ & Ket \\
\hline \multirow[t]{3}{*}{ Sudah dilakukan sesuai KD } & $\mathrm{Ya}$ & 2 & Pilihan & 2 & Pilihan & 2 & Pilihan \\
\hline & Tidak & 0 & - & 0 & - & 0 & - \\
\hline & Tidak tahu & 0 & - & 0 & - & 0 & - \\
\hline \multirow{3}{*}{$\begin{array}{l}\text { Pembelajaran sastra sudah seimbang } \\
\text { dengan pembelajaran bahasa }\end{array}$} & $\mathrm{Ya}$ & 0 & - & 0 & & 1 & - \\
\hline & Tidak & 2 & Pilihan & 2 & Pilihan & 1 & - \\
\hline & Tidak tahu & 0 & - & 0 & - & 0 & - \\
\hline \multirow{3}{*}{$\begin{array}{l}\text { Setiap pembelajaran bahasa dan sastra } \\
\text { diberi wacana / cerita }\end{array}$} & $\mathrm{Ya}$ & 0 & - & 0 & - & 1 & - \\
\hline & Tidak & 2 & Pilihan & 2 & Pilihan & 1 & - \\
\hline & Tidak tahu & 0 & - & 0 & - & 0 & \\
\hline \multirow{3}{*}{$\begin{array}{l}\text { Setiap pembelajaran cerita selalu diberi } \\
\text { cerita anak }\end{array}$} & $\mathrm{Ya}$ & 2 & Pilihan & 2 & Pilihan & 2 & Pilihan \\
\hline & Tidak & 0 & - & 0 & - & 0 & - \\
\hline & Tidak tahu & 0 & - & 0 & - & 0 & - \\
\hline \multirow{3}{*}{$\begin{array}{l}\text { Siswa sering membaca cerita secara } \\
\text { individu }\end{array}$} & $\mathrm{Ya}$ & 2 & Pilihan & 2 & Pilihan & 2 & Pilihan \\
\hline & Tidak & 0 & - & 0 & - & 0 & - \\
\hline & Tidak tahu & 0 & - & 0 & - & 0 & - \\
\hline \multirow{3}{*}{$\begin{array}{l}\text { Mengalami kendala penyediaan cerita } \\
\text { anak }\end{array}$} & $\mathrm{Ya}$ & 2 & Pilihan & 2 & Pilihan & 1 & - \\
\hline & Tidak & 0 & - & 0 & - & 1 & - \\
\hline & Tidak tahu & 0 & - & 0 & - & 0 & - \\
\hline \multirow[t]{3}{*}{ Kendala dalam bercerita } & $\mathrm{Ya}$ & 2 & Pilihan & 2 & Pilihan & 2 & Pilihan \\
\hline & Tidak & 0 & - & 0 & - & 0 & - \\
\hline & Tidak tahu & 0 & - & 0 & - & 0 & - \\
\hline \multirow[t]{3}{*}{ Cerita anak yang dimiliki guru terbatas } & $\mathrm{Ya}$ & 2 & Pilihan & 2 & Pilihan & 1 & - \\
\hline & Tidak & 0 & - & 0 & - & 1 & - \\
\hline & Tidak tahu & 0 & - & 0 & - & 0 & - \\
\hline \multirow{3}{*}{$\begin{array}{l}\text { Cerita yang diberikan siswa hanya yang } \\
\text { ada dalam buku pelajaran }\end{array}$} & $\mathrm{Ya}$ & 2 & Pilihan & 2 & Pilihan & 2 & Pilihan \\
\hline & Tidak & 0 & - & 0 & - & 0 & - \\
\hline & Tidak tahu & 0 & - & 0 & - & 0 & - \\
\hline \multirow[t]{3}{*}{ Guru memiliki koleksi buku cerita } & $\mathrm{Ya}$ & 0 & - & 1 & - & 0 & - \\
\hline & Tidak & 2 & Pilihan & 1 & - & 2 & Pilihan \\
\hline & Tidak tahu & 0 & - & 0 & - & 0 & - \\
\hline \multirow{2}{*}{$\begin{array}{l}\text { Guru pernah menyajikan cerita dalam } \\
\text { bentuk bercerita / mendongeng }\end{array}$} & $\mathrm{Ya}$ & 1 & - & 0 & - & 0 & - \\
\hline & Tidak & 1 & - & 2 & Pilihan & 2 & Pilihan \\
\hline \multirow[t]{3}{*}{ Frekuensi guru dalam bercerita } & 1 bulan $1 x$ & 2 & Pilihan & 2 & Pilihan & 2 & Pilihan \\
\hline & 1 bulan $>1$ & 0 & - & 0 & - & 0 & - \\
\hline & 1 minggu 1 kali & 0 & - & 0 & - & 0 & - \\
\hline \multirow{2}{*}{$\begin{array}{l}\text { Guru menggunakan media dalam } \\
\text { bercerita }\end{array}$} & $\mathrm{Ya}$ & 0 & - & 0 & - & 0 & - \\
\hline & Tidak & 2 & Pilihan & 2 & Pilihan & 2 & Pilihan \\
\hline
\end{tabular}

Pada Tabel 3 , peneliti mendapatkan data tentang gambaran pembelajaran bercerita di kelas oleh guru. Kesimpulan dari Tabel 3 adalah bahwa guru tidak memiliki koleksi buku cerita anak. Guru hanya terpaku pada materi cerita yang ada dalam buku pelajaran. Keterbatasan inilah yang kemudian mengakibatkan metode yang digunakan oleh guru menjadi monoton.

Pembahasan selanjutnya adalah tentang kriteria cerita anak pada aspek penutur cerita yang tampak pada Tabel 4 di bawah ini. 
Tabel 4. Kriteria Cerita Anak Pada Aspek Penutur Cerita

\begin{tabular}{|c|c|c|c|c|c|c|c|}
\hline \multirow{3}{*}{ Responden } & \multirow{3}{*}{ Jawaban } & \multicolumn{6}{|c|}{ Sekolah } \\
\hline & & \multicolumn{2}{|c|}{ SD N Pendrikan Lor 02} & \multicolumn{2}{|c|}{ SD Bungangan 03} & \multicolumn{2}{|c|}{ MI Nasharul Fajar } \\
\hline & & Jml & Ket & $\mathrm{Jml}$ & Ket & Jml & Ket \\
\hline \multirow[t]{2}{*}{ Siswa } & Anak-anak & 20 & Pilihan & 7 & Pilihan & 20 & - \\
\hline & Orang dewasa & 48 & - & 49 & - & 50 & Pilihan \\
\hline \multirow[t]{2}{*}{ Guru } & Anak-anak & 0 & - & 0 & - & 0 & - \\
\hline & Orang dewasa & 2 & Pilihan & 2 & - & 2 & Pilihan \\
\hline \multirow[t]{2}{*}{ Orang tua } & Anak-anak & 0 & - & 0 & - & 0 & - \\
\hline & Orang dewasa & 3 & - & 3 & Pilihan & 4 & Pilihan \\
\hline
\end{tabular}

Berdasarkan Tabel 4 terlihat bahwa penutur cerita anak yang diminati oleh siswa adalah penutur dewasa, misalnya guru, orang tua mereka, kakek, nenek, atau pendongeng. Semua guru dan orang tua pun memilih orang dewasa sebagai penutur cerita anak.

Hal selanjutnya yang dibahas adalah tentang kriteria anak pada aspek tokoh cerita yang ditampilkan pada Tabel 5 menunjukkan bahwa tokoh cerita yang paling diminati oleh responden adalah tokoh manusia yang masih berusia anak-anak.

Tabel 5. Kriteria Cerita Anak Pada Aspek Tokoh Cerita

\begin{tabular}{|c|c|c|c|c|c|c|c|c|}
\hline \multirow{3}{*}{ Indikator } & \multirow{3}{*}{ Responden } & \multirow{3}{*}{ Jawaban } & \multicolumn{6}{|c|}{ Sekolah } \\
\hline & & & \multicolumn{2}{|c|}{ SD N Pendrikan Lor 02} & \multicolumn{2}{|c|}{ SD Bungangan 03} & \multicolumn{2}{|c|}{ MI Nasharul Fajar } \\
\hline & & & $\mathrm{Jml}$ & Ket & $\mathrm{Jml}$ & Ket & $\mathrm{Jml}$ & Ket \\
\hline \multirow[t]{6}{*}{ Usia Tokoh } & Siswa & Anak-anak & 56 & Pilihan & 48 & Pilihan & 39 & Pilihan \\
\hline & & Orang dewasa & 12 & . & 8 & - & 31 & - \\
\hline & Guru & Anak-anak & 2 & Pilihan & 2 & Pilihan & 2 & Pilihan \\
\hline & & Orang dewasa & 0 & - & 0 & - & 0 & - \\
\hline & Orang tua & Anak-anak & 3 & Pilihan & 3 & Pilihan & 4 & Pilihan \\
\hline & & Orang dewasa & 0 & - & 0 & - & 0 & - \\
\hline
\end{tabular}

Hal selanjutnya yang dibahas adalah tentang kriteria cerita anak pada aspek tema cerita yang tampak pada Tabel 6 . Tampak bahwa tema cerita yang paling banyak diminati siswa adalah tentang petualangan, misteri atau sihir, dan tolong menolong. Guru memilih tema kehidupan di sekitar anak-anak, dan orang tua memilih tema kejujuran, kerja keras, tolong menolong, dan kesabaran.

Tabel 6. Kriteria Cerita Anak Pada Aspek Tema Cerita

\begin{tabular}{|c|c|c|c|c|c|c|c|}
\hline \multirow{3}{*}{ Responden } & \multirow{3}{*}{ Jawaban } & \multicolumn{6}{|c|}{ Sekolah } \\
\hline & & \multicolumn{2}{|c|}{ SD N Pendrikan Lor 02} & \multicolumn{2}{|c|}{ SD Bungangan 03} & \multicolumn{2}{|c|}{ MI Nasharul Fajar } \\
\hline & & Jml & Ket & $\mathrm{Jml}$ & Ket & Jml & Ket \\
\hline \multirow[t]{7}{*}{ Siswa } & Petualangan & 33 & Pilihan & 40 & Pilihan & 34 & Pilihan \\
\hline & Kepahlawanan & 23 & - & 12 & - & 17 & - \\
\hline & Kejujuran & 42 & Pilihan & 37 & Pilihan & 24 & - \\
\hline & Kerja keras & 21 & - & 17 & - & 18 & - \\
\hline & Tolong menolong & 26 & - & 20 & Pilihan & 45 & Pilihan \\
\hline & Misteri/sihir & 37 & Pilihan & 16 & - & 31 & Pilihan \\
\hline & Kesabaran & 21 & - & 12 & - & 25 & - \\
\hline \multirow[t]{3}{*}{ Guru } & Petualangan & 0 & - & 0 & - & 0 & - \\
\hline & Pahlawan & 0 & - & 0 & - & 0 & - \\
\hline & Kehidupan anak & 2 & Pilihan & 2 & Pilihan & 2 & Pilihan \\
\hline
\end{tabular}


LANJUTAN Tabel 6.

\begin{tabular}{llcccccc}
\hline \multirow{3}{*}{ Responden } & \multirow{2}{*}{ Jawaban } & \multicolumn{7}{c}{ Sekolah } \\
\cline { 3 - 8 } & & \multicolumn{2}{c}{ SD N Pendrikan Lor 02 } & \multicolumn{2}{c}{ SD Bungangan 03 } & \multicolumn{2}{c}{ MI Nasharul Fajar } \\
\cline { 2 - 7 } Orang tua & Jml & Ket & Jml & Ket & Jml & Ket \\
& Ketualangan & 3 & Pilihan & 2 & - & 2 & - \\
& Kejujlawanan & 1 & - & 2 & - & 3 & - \\
& Kerja keras & 2 & - & 3 & Pilihan & 3 & - \\
& Tolong menolong & 3 & Pilihan & 3 & Pilihan & 4 & Pilihan \\
& Misteri/sihir & 3 & Pilihan & 3 & Pilihan & 4 & Pilihan \\
& Kesabaran & 0 & - & 0 & - & 0 & - \\
& 2 & - & 2 & - & 4 & Pilihan \\
\hline
\end{tabular}

Fokus penelitian selanjutnya adalah tentang kriteria cerita anak pada aspek latar cerita. Diperoleh data bahwa siswa lebih memilih latar cerita di sekolah, rumah, dan lapangan. Begitupun dengan guru dan orang tua yang memilih latar cerita kehidupan nyata yang dapat dijumpai oleh anak, yaitu orang tua, sekolah, rumah, dan pegunungan. Hasilnya tampak pada Tabel 7.

Tabel 7. Kriteria Cerita Anak Pada Aspek Tema Cerita

\begin{tabular}{|c|c|c|c|c|c|c|c|}
\hline \multirow{3}{*}{ Responden } & \multirow{3}{*}{ Jawaban } & \multicolumn{6}{|c|}{ Sekolah } \\
\hline & & \multicolumn{2}{|c|}{ SD N Pendrikan Lor 02} & \multicolumn{2}{|c|}{ SD Bungangan 03} & \multicolumn{2}{|c|}{ MI Nasharul Fajar } \\
\hline & & $\mathrm{Jml}$ & Ket & $\mathrm{Jml}$ & Ket & $\mathrm{Jml}$ & Ket \\
\hline \multirow[t]{8}{*}{ Siswa } & Sekolah & 22 & Pilihan & 16 & Pilihan & 16 & Pilihan \\
\hline & Rumah & 38 & Pilihan & 39 & Pilihan & 33 & Pilihan \\
\hline & Hutan & 5 & - & 9 & - & 5 & - \\
\hline & Lapangan & 6 & . & 23 & Pilihan & 18 & Pilihan \\
\hline & Sawah & 12 & Pilihan & 11 & - & 5 & - \\
\hline & Pasar & 3 & - & 12 & - & 7 & - \\
\hline & Supermarket & 3 & - & 1 & - & 1 & - \\
\hline & Pegunungan & 8 & - & 7 & - & 13 & - \\
\hline Guru & $\begin{array}{l}\text { Kehidupan nyata yang dijumpai } \\
\text { anak }\end{array}$ & 2 & Pilihan & 2 & Pilihan & 2 & Pilihan \\
\hline \multirow[t]{8}{*}{ Orang tua } & Sekolah & 0 & - & 0 & - & 1 & - \\
\hline & Rumah & 3 & Pilihan & 3 & Pilihan & 4 & Pilihan \\
\hline & Hutan & 2 & - & 3 & Pilihan & 3 & Pilihan \\
\hline & Lapangan & 2 & - & 3 & Pilihan & 2 & - \\
\hline & Sawah & 0 & - & 0 & - & 2 & - \\
\hline & Pasar & 1 & - & 2 & - & 2 & - \\
\hline & Supermarket & 0 & & 1 & - & 1 & - \\
\hline & Pegunungan & 3 & Pilihan & 2 & - & 4 & Pilihan \\
\hline
\end{tabular}

Selanjutnya, dibahas tentang kriteria cerita anak pada alur cerita. Sebagian besar siswa, guru, dan orang tua memilih alur lurus dan tunggal. Hal ini memudahkan siswa dalam memahami isi cerita jika cerita disampaikan secara runtut dari awal hingga akhir cerita. Hasilnya tampak pada Tabel 8 .

Pada pembahasan ini, dibahas kriteria cerita anak pada aspek jenis cerita. Siswa, guru, dan orang tua memilih cerita yang bersumber pada keadaan nyata yang bukan khayalan. Hal ini memudahkan siswa dalam memahami isi cerita. Hasilnya ditampilkan dalam Tabel 9. 
Tabel 8. Kriteria Cerita Anak Pada Aspek Alur/Jalan Cerita

\begin{tabular}{llcccccc}
\hline \multirow{2}{*}{ Responden } & \multirow{2}{*}{ Jawaban } & \multicolumn{9}{c}{ Sekolah } \\
\cline { 3 - 7 } & & \multicolumn{2}{c}{ SD N Pendrikan Lor 02 } & \multicolumn{2}{c}{ SD Bungangan 03 } & \multicolumn{2}{c}{ MI Nasharul Fajar } \\
\cline { 2 - 7 } & & Jml & Ket & Jml & Ket & Jml & Ket \\
\hline Siswa & Lurus/runtut & 55 & Pilihan & 24 & Pilihan & 52 & Pilihan \\
& Masa lalu/ flashback & 13 & - & 8 & - & 15 & - \\
\multirow{3}{*}{ Guru } & Tidak runtut & 0 & - & 0 & - & 3 & - \\
Orang tua & Lurus dan tunggal & 2 & Pilihan & 2 & Pilihan & 2 & Pilihan \\
& Lurus/runtut & 3 & Pilihan & 3 & Pilihan & 3 & Pilihan \\
& Masa lalu/ flashback & 0 & - & 0 & - & 0 & - \\
\hline
\end{tabular}

Tabel 9. Kriteria Cerita Anak Pada Aspek Jenis Cerita

\begin{tabular}{llcccccc}
\hline \multirow{2}{*}{ Responden } & \multirow{2}{*}{ Jawaban } & \multicolumn{5}{c}{ Sekolah } \\
\cline { 3 - 7 } & & \multicolumn{2}{c}{ SD N Pendrikan Lor 02 } & \multicolumn{2}{c}{ SD Bungangan 03 } & \multicolumn{2}{c}{ MI Nasharul Fajar } \\
\cline { 3 - 7 } & Nyata & 62 & Ket & Jml & Ket & Jml & Ket \\
\hline \multirow{2}{*}{ Siswa } & Khayalan & 6 & - & 0 & Pilihan & 60 & Pilihan \\
\multirow{3}{*}{ Guru } & Fiksi realistis/nyata & 2 & Pilihan & 2 & Pilihan & 10 & - \\
Orang tua & Nyata & 3 & Pilihan & 3 & Pilihan & 4 & Pilihan \\
& Khayalan & 0 & - & 0 & - & 0 & - \\
\hline
\end{tabular}

Profil media boneka tangan menjadi pembahasan selanjutnya. Sebagian besar siswa dan guru memilih media bercerita yang cocok adalah buku, gambar, dan boneka tangan. Bentuk media yang dipilih adalah yang berukuran sedang dan memiliki warna yang cerah. Bahan yang dipilih untuk membuat boneka tangan adalah kain katun dan kain flanel yang dibuat sesuai ukuran tangan. Hasilnya tampak pada Tabel 10.

Tabel 10. Kriteria Cerita Anak Pada Aspek Media Cerita

\begin{tabular}{|c|c|c|c|c|c|c|c|c|}
\hline \multirow{3}{*}{ Responden } & \multirow{3}{*}{ Indikator } & \multirow{3}{*}{ Jawaban } & \multicolumn{6}{|c|}{ Sekolah } \\
\hline & & & \multicolumn{2}{|c|}{ SD N Pendrikan Lor 02} & \multicolumn{2}{|c|}{ SD Bungangan 03} & \multicolumn{2}{|c|}{ MI Nasharul Fajar } \\
\hline & & & Jml & Ket & Jml & Ket & Jml & Ket \\
\hline \multirow[t]{20}{*}{ Siswa } & \multirow[t]{4}{*}{ Bentuk media bercerita } & Buku & 42 & Pilihan & 36 & Pilihan & 36 & Pilihan \\
\hline & & Gambar & 6 & - & 12 & - & 19 & - \\
\hline & & Boneka tangan & 46 & Pilihan & 48 & Pilihan & 52 & Pilihan \\
\hline & & Wayang & 2 & - & 10 & - & 12 & - \\
\hline & \multirow[t]{3}{*}{ Ukuran media } & Kecil & 5 & - & 0 & - & 3 & - \\
\hline & & Sedang (A5) & 55 & Pilihan & 49 & Pilihan & 57 & Pilihan \\
\hline & & Besar (A 4) & 8 & 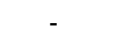 & 7 & - & 13 & - \\
\hline & \multirow{3}{*}{ Warna media } & Putih & 12 & - & 15 & - & 14 & - \\
\hline & & Berwarna cerah & 42 & Pilihan & 41 & Pilihan & 56 & Pilihan \\
\hline & & Berwarna lembut & 14 & - & 0 & - & 0 & - \\
\hline & \multirow{4}{*}{ Bahan boneka } & Kain katun & 16 & Pilihan & 22 & Pilihan & 15 & Pilihan \\
\hline & & Kain flanel & 54 & Pilihan & 50 & Pilihan & 58 & Pilihan \\
\hline & & Kertas & 3 & 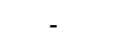 & 8 & - & 2 & - \\
\hline & & Kaos kaki & 2 & - & 10 & - & 6 & - \\
\hline & \multirow{3}{*}{ Ukuran boneka tangan } & Besar & 2 & - & 8 & - & 6 & - \\
\hline & & $\begin{array}{l}\text { Sedang/sesuai } \\
\text { ukuran tangan }\end{array}$ & 64 & Pilihan & 43 & Pilihan & 58 & Pilihan \\
\hline & & Kecil & 2 & - & 5 & - & 6 & - \\
\hline & \multirow[t]{3}{*}{ Warna boneka tangan } & Hitam-putih & 1 & - & 0 & - & 2 & - \\
\hline & & Berwarna cerah & 59 & Pilihan & 48 & Pilihan & 60 & Pilihan \\
\hline & & Berwarna lembut & 8 & & & - & 8 & - \\
\hline
\end{tabular}


Yang terakhir, dibahas tentang profil kegiatan bercerita. Bahasa pengantar cerita yang dipahami oleh siswa dan guru adalah bahasa Indonesia yang lugas dan sederhana. Hal ini membuat siswa lebih mudah dalam memahami cerita yang disampaikan. Siswa memilih kalimat yang panjangnya variatif. Hasilnya tampak pada tabel 11 .

Tabel 11. Profil Kegiatan Bercerita

\begin{tabular}{|c|c|c|c|c|c|c|c|c|}
\hline \multirow{3}{*}{ Responden } & \multirow{3}{*}{ Indikator } & \multirow{3}{*}{ Jawaban } & \multicolumn{6}{|c|}{ Sekolah } \\
\hline & & & \multicolumn{2}{|c|}{ SD N Pendrikan Lor 02} & \multicolumn{2}{|c|}{ SD Bungangan 03} & \multicolumn{2}{|c|}{ MI Nasharul Fajar } \\
\hline & & & Jml & Ket & Jml & Ket & $\mathrm{Jml}$ & Ket \\
\hline \multirow[t]{9}{*}{ Siswa } & Bahasa yang & Baku & 5 & 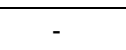 & 10 & - & 5 & - \\
\hline & dipahami & Lugas, sederhana & 55 & Pilihan & 46 & Pilihan & 61 & Pilihan \\
\hline & & Gaul & 8 & - & 0 & - & 4 & - \\
\hline & Bahasa dalam & Baku & 3 & ـ & 1 & - & 10 & - \\
\hline & cerita & Lugas, sederhana & 58 & Pilihan & 49 & Pilihan & 57 & Pilihan \\
\hline & & Gaul & 7 & - & 6 & - & 3 & - \\
\hline & Kalimat dalam & Pendek & 12 & - & 13 & - & 12 & - \\
\hline & cerita & Panjang & 6 & 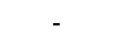 & 11 & - & 10 & - \\
\hline & & Bervariasi & 50 & Pilihan & 28 & Pilihan & 48 & Pilihan \\
\hline \multirow[t]{9}{*}{ Guru } & Bahasa yang & Baku & 0 & - & 0 & - & 0 & - \\
\hline & dipahami & Lugas, sederhana & 2 & Pilihan & 2 & Pilihan & 2 & Pilihan \\
\hline & & Gaul & 0 & - & 0 & - & 0 & - \\
\hline & Bahasa dalam & Baku & 0 & - & 0 & - & 0 & - \\
\hline & cerita & Lugas, sederhana & 2 & Pilihan & 2 & Pilihan & 2 & Pilihan \\
\hline & & Gaul & 0 & - & 0 & - & 0 & - \\
\hline & Kalimat dalam & Pendek & 0 & - & 0 & - & 0 & - \\
\hline & cerita & Panjang & 0 & - & 0 & - & 0 & - \\
\hline & & Bervariasi & 2 & Pilihan & 2 & Pilihan & 2 & Pilihan \\
\hline
\end{tabular}

Pengembangan media boneka tangan dilaksanakan untuk menindaklanjuti hasil analisis kebutuhan yang telah diperoleh melalui pengisian angket oleh siswa, guru, dan orang tua. Kegiatan diawali dengan penyusunan draf cerita anak dan membuat media boneka tangan yang sesuai dengan cerita dan selanjutnya dikonsultasikan dan dimintakan penilaian dari ahli. Setelah cerita ditentukan, peneliti membuat boneka tangan yang sesuai dengan cerita untuk media bercerita. Bahan yang dipilih untuk membuat boneka tangan adalah perpaduan dari kain katun dan kain flanel yang dihias dengan ornamen-ornamen pendukung, seperti mata kocak, renda, kain wol, dan sebagainya yang dibuat dengan bantuan benang dan jarum, lem kayu, lem kain, velkro, dakron, untuk rambut, mata, hidung, mulut yang mendekati obyek aslinya supaya menarik.

\section{SIMPULAN}

Berdasarkan hasil penelitian yang telah dilakukan, didapatkan kesimpulan sebagai berikut. (1) Kriteria cerita anak adalah yang dapat dituturkan atau diceritakan oleh orang dewasa, bertokoh manusia dan berusia anak-anak (jika ada tokoh dewasa, perannya adalah sebagai penyampai sikap yang salah atau benar), bertema petualangan (atau misteri/sihir, dan tolong menolong), latar cerita di tempat yang dapat dijumpai anak-anak dalam kehidupan nyata (misalnya di lapangan, pegunungan, sawah, pasar, atau rumah), jenis cerita bersumber dari kisah nyata atau cerita yang terinspirasi dari kisah nyata, dan amanat harus mengandung unsur nilai-nilai positif (anak-anak akan membayangkannya karena latar, tokoh, dan konflik seolah-olah nyata atau dekat dengan anak, dan 
(2) media boneka tangan yang sesuai dengan kebutuhan siswa dan guru adalah media boneka tangan yang terbuat dari kain flannel dan kain katun berukuran sedang (atau sesuai dengan ukuran tangan) dan memiliki warna-warna cerah yang menarik perhatian.

\section{SARAN}

Berdasarkan hasil penelitian maka peneliti menyarankan agar guru dan orang tua memperhatikan kebutuhan cerita siswa/anak untuk menambah wawasan dan menanamkan nilai karakter. Guru sebaiknya menggunakan media bercerita misalnya media boneka tangan untuk menarik minat siswa dan memudahkan pemahaman siswa.

\section{REFERENSI}

Arikunto, S. (2000). Prosedur penelitian suatu pendekatan praktek. Jakarta: Rineka Cipta. Arsyad, A. (2011). Media pembelajaran. Jakarta: Rajawali Press.

Gall, Meredith D., Joyce P. Gall, dan Walter R. Borg. (2002). Educational research and introduction. USA: Pearson Educations.

Nurgiyantoro, B. (2005). Sastra anak pengantar pemahaman dunia anak. Yogyakarta: Gadjah Mada University Press.

Sukmadinata, N. S. (2008). Metode penelitian pendidikan. Bandung: Remaja Rosdakarya.

Sulianto, Joko, Mei Fita Asri Untari, dan Fitri Yulianti. (2014). Pengembangan media boneka tangan dalam metode bercerita untuk penanaman karakter pada siswa Sekolah Dasar. Semarang: Laporan Penelitian, belum terpublikasikan.

Suparno, Paul, Moerti Yoedho Koesoemo, Detty Titisati, A.I. (2002). Pendidikan budi pekerti di sekolah: sebuah tinjauan umum. Yogyakarta: Kanisius.

Zuriah, N. (2007). Pendidikan moral dan budi pekerti dalam perspektif perubahan. Jakarta: Bumi Aksara. 